\title{
A Study of Suicidal Tendency among Annamalai University Students
}

\author{
M. Amin Wani ${ }^{1}$, Dr. R. Sankar ${ }^{2}$, Binshad M. ${ }^{3}$, Nargees S. ${ }^{3}$, Anicham J. ${ }^{3}$
}

\section{ABSTRACT}

Objective: - Suicide is third leading cause of death among modern youth and second leading cause of death among college students. The present study examined effect of gender and faculty on suicidal tendency among students. Method: - This study is based on sample of 100 students divided into two groups 50 males and 50 females. In each group 25 students have science \& 25 have arts subjects. Samples were selected through sample random sampling method. The suicidal tendency among the students was measured by Suicidal Tendency Scale constructed by Dr. D. J. Bhatt and Dr. R. G. Meghnathi. Mean \& ANOVA were applied for data analysis. Results: - The results of the present study demonstrated that female student's shows high suicidal tendency than male students as the mean score of female students (74.38) is more than mean score of male students (71.06). Results also revealed that students from science faculty have also high suicidal tendency than arts students as the obtained mean scores of science students (76.88) is more than mean scores of students of arts faculty (68.56). Conclusions: - Female and science students have high suicidal tendency than male students and arts students.

Keywords: Suicidal tendency, Gender and Faculty.

The term "Suicide" is derived from the Latin word "Suicidium" means "to kill oneself". Sir Thomas Browne was the first person who used the term suicide in his "Religio Medici” in 1642. Suicide is an act of self killing, self destruction or self murder. Suicide is $2^{\text {nd }}$ leading cause of death in young generation. The CDC reported that suicide is the $3^{\text {rd }}$ leading cause of death among 15- 24 year olds in the United States. Since past few decades this evil is increasing rapidly in all over world. Every year more than one million people kill themselves globally. Every year 1100 college students commit suicides and 50\% report suicidal ideation at some time in their life. The main factors of suicide among students are academic stress, depression, hopelessness, sexual abuse,

\footnotetext{
${ }^{1}$ Ph.D Research Scholar of Psychology Annamalai University Tamil Nadu, India.

${ }^{2}$ Assistant Professor Department of Psychology Annamalai University Tamil Nadu, India

${ }^{3}$ M.Sc. Clinical Psychology Students,Department of Psychology Annamalai University Tamil Nadu, India.

*Responding Author

(C) 2016 I A Wani, R. Sankar, Binshad M, Nargees S, Anicham J; licensee IJIP. This is an Open Access Research distributed under the terms of the Creative Commons Attribution License (http://creativecommons.org/licenses/by/2.0), which permits unrestricted use, distribution, and reproduction in any Medium, provided the original work is properly cited.
} 
failure in examination, broken families, anger, financial problems, ineffective problem solving skills, feeling of loneliness, isolation and love breakups etc. Furr et al., (2001) ${ }^{1}$ found that conflict with boy friend or girl friend is a major cause of suicide in college students. Dr Anuradha Bose, associate professor in pediatrics says that "suicide is the 3rd largest single cause of death among Indian youth between the ages of 15-19. One in every three cases of suicide in India is committed by people due to academic pressure."

Suicidal tendencies involves ideas, thinking, taking about suicide, it also involves making an attempt to take one's own life, or completing suicide.

In India the rate of suicide is rapidly growing every year which is alarming. According to W.H.O. in India suicidal rate (21.1\%) is higher as compare to the other countries in the world. Every year more than 1 lakh persons commit suicide in India which is $20 \%$ of suicide cases globally. In India in every 15 minutes 1 case of suicide is recorded.

Total no of suicides during 2010 to 2014 in India

\begin{tabular}{|l|l|l|}
\hline S. No. & Year & Total Number of Suicides \\
\hline 01 & 2010 & $1,34,599$ \\
\hline 02 & 2011 & $1,35,585$ \\
\hline 03 & 2012 & $1,35,445$ \\
\hline 04 & 2013 & $1,34,799$ \\
\hline 05 & 2014 & $1,31,666$ \\
\hline
\end{tabular}

States with higher percentage of suicides during 2012 to 2014

\begin{tabular}{|l|l|l|l|}
\hline S.No & $\mathbf{2 0 1 2}$ & $\mathbf{2 0 1 3}$ & $\mathbf{2 0 1 4}$ \\
\hline 01 & Tamil Nadu (14.0\%) & Maharashtra (12.3\%) & Maharashtra (12.4\%) \\
\hline 02 & Maharashtra (13.4\%) & Tamil Nadu (12.3\%) & Tamil Nadu (12.2\%) \\
\hline 03 & Andhra Pradesh (11.8\%) & Andhra Pradesh (10.8\%) & West Bengal (10.9\%) \\
\hline 04 & Karnataka (10.6\%) & West Bengal (9.7\%) & Karnataka (8.3\%) \\
\hline 05 & Madhya Pradesh (8.1\%) & Karnataka (8.4\%) & Telangana (7.3\%) \\
\hline
\end{tabular}

Among the India's 53 mega cities Chennai, Bangalore, Delhi and Mumbai together reported 34.7 \% of the total suicides. According to NCRB report in India rate of suicides was 10.6 in 2014.

Rich source of literature is available on suicidal tendency among students. Every year huge number of research's is conducted by researchers throughout the world like Bhalala (2014) ${ }^{2}$ revealed that female and urban students showed higher level of suicide tendency then male and rural students. Zheng \& Wang (2014) $)^{3}$ found that female medical students have higher rate of suicidal tendency. Kumar et al., (2012) ${ }^{4}$ in their study found that suicidal ideation was more among depressed students; also it was high among those students who live in hostel and nuclear families. Results also revealed that suicidal ideation was significantly high among the depressed female students. 
Danie et al., (2012) $)^{5}$ revealed that adolescent girls had significantly higher rates of deliberate selfharm and suicidal behavior than adolescent boys. Ishita \& Jayanti $(2010)^{6}$ revealed that about $12.5 \%$ of the students had high suicidal ideation. Amelia et al., (2009) ${ }^{7}$ investigate suicide ideation among college students. Results revealed that $6 \%$ of 1 st year students had current suicide ideation. Arun \& Chavan (2009) ${ }^{8}$ investigated stress and suicidal ideas in adolescent students. They found that out of 2402 students, 122 (6\%) reported suicidal ideas and 8 (0.39\%) students reported suicidal attempt. Liselotte et al., (2008) ${ }^{9}$ found that $49.6 \%$ medical students experience burnout and $11.2 \%$ experience suicidal ideation during their college life. Crosby et al., $(1999)^{10}$ found that rate of suicidal ideation among medical students is $11.2 \%$ which is higher than the rate of suicide ideation among age group in the general population which is $6.9 \%$. Rey et al., $(1998)^{11}$ in their study reported that about $26 \%$ adolescents between the ages of 15 to 20 year had suicidal thoughts, $15 \%$ had suicidal plans and 3\% had suicide attempts.

\section{Statement of the problem: -}

To study the effect of gender and faculty on suicidal tendency among university students.

\section{OBJECTIVES}

1. To find the effect of gender on suicidal tendency among students.

2. To find the effect of faculty on suicidal tendency among students.

3. To find the interaction effect of gender and faculty on suicidal tendency among students.

\section{Hypotheses}

1. There is significant effect of gender on suicidal tendency among students.

2. There is significant effect of faculty on suicidal tendency among students.

3. There is significant interaction effect of gender and faculty on suicidal tendency among students.

\section{Variables}

An experimental variable is gender (Male and Female) and faculty (Science and Arts) and the criterion variable is suicidal tendency.

\section{Sample}

In the present study the investigator take sample of 100 students in the Annamalai University campus. These 100 subjects were equally divided into two main groups (male and female). Further these two groups were divided into two more sub-groups (Science and Arts). Samples were selected through sample random sampling method.

\section{Measuring tool}

Suicidal Tendency Scale constructed by Dr. D. J. Bhatt and Dr. R. G. Maghnathi was used to measure the suicidal tendency among university students. The scale consists of 40 items. The reliability of the scale was measured by test retest method and was found $0.83 \& 0.92$ respectively. 


\section{RESULTS}

The present research endeavor was aimed to find out the effect of gender and faculty on suicidal tendency. For this purpose the data was collected from Annamalai University students by using Suicidal Tendency Scale constructed by Dr. D. J. Bhatt and Dr. R. G. Maghnathi. The obtained scores were assigned for different responses according to the item. The scores were arranged in tabular form to find Mean value; ANOVA was applied to test hypotheses. The obtained results are shown in tables given below.

Table-1, Showing mean scores of male and female students

\begin{tabular}{|l|l|l|}
\hline Gender & No & Mean \\
\hline Male & 50 & 71.06 \\
\hline Female & 50 & 74.38 \\
\hline
\end{tabular}

Table-2, Showing mean scores of science and arts students

\begin{tabular}{|l|l|l|}
\hline Faculty & No & Mean \\
\hline Science & 50 & 76.88 \\
\hline Arts & 50 & 68.56 \\
\hline
\end{tabular}

Table-3, Showing ANOVA Suicidal Tendency score of gender and faculty

\begin{tabular}{|l|l|l|l|l|l|}
\hline Source of variation & Score of variation & df & M. S & F-value & P-value \\
\hline Gender (A) & 1730.56 & 1 & 1730.56 & $5.11^{*}$ & $\mathrm{P}<0.05$ \\
\hline Faculty (B) & 275.56 & 1 & 275.56 & 0.81 & $\mathrm{P}>0.05$ \\
\hline Interaction (AxB) & 88.36 & 1 & 88.36 & 0.26 & $\mathrm{P}>0.05$ \\
\hline Within Group & 32485.68 & 96 & 338.39 & & \\
\hline Total & 34580.16 & 99 & & & \\
\hline
\end{tabular}

denotes significant at 0.05 level of significance.

\section{DISCUSSION}

The results of present study demonstrated that female students shows high suicidal tendency than male students as the mean score of female students (74.38) is more than mean score of male students (71.06) same results are found by Sharma et al., (2008) ${ }^{12}$ they found female students report more suicidal tendencies than male students. Students from science faculty have also high suicidal tendency than arts students also mean scores of students of science faculty (76.88) is more than mean scores of students of arts faculty (68.56). This finding is supported by the study conducted by Kunmi et al., (2014) ${ }^{13}$ they revealed that depression and suicidal ideation are high in medical students.

A close look at the ANOVA table indicates that the obtained F-value of the $1^{\text {st }}$ experimental variable (gender) was found significant at 0.05 level [F-(99, 1$)=5.11, \mathrm{P}<.05]$. Therefore our first hypothesis gender has significant effect on suicidal tendency among students is accepted. Our findings bear some similarities with those of previous studies conducted by various researchers like 
Chan et al., (2009) ${ }^{14}$ found that females had significantly higher rates of lifetime suicide ideation than males. Second hypothesis is also rejected as the obtained F-value (0.81) of the 2nd experimental variable (faculty) was found insignificant at 0.05 level [F-(99, 1) $=0.81, \mathrm{P}>.05]$. Similarly 3rd hypothesis is also rejected as the obtained F-value 0.26 is also found less than tabulation value at 0.05 level $[\mathrm{F}-(99,1)=0.26, \mathrm{P}>.05]$. Thus we may say that there is no significant interaction effect of gender and faculty on suicidal tendency among students.

\section{CONCLUSION}

To sum up, taking into account the results of the current study, we might conclude that female and science students have high suicidal tendency than male students and arts students.

\section{REFERENCES}

1. Furr, S., R., Westefeld, J., S., McConnell, G., N., \& Jenkins, M., J. (2001). Suicide and depression among college students. Professional Psychological Research and Practice, 32: 97100.

2. Bhalala J., N. (2014). A comparative study of suicide tendency among students in relation to gender and residential area. The International Journal of Indian Psychology, 2, 1:36-40.

3. Zheng, A., \& Wang Z. (2014). Social and psychological factors of the suicidal tendencies of Chinese medical students. Bio Psycho Social Medicine, 14, 23:1-4.

4. Vinod, K., Nagendra, K., Sanjay, D., Gouli, C., \& Kalappanavar, N., K. (2012). Prevalence and association of depression and suicidal tendency among adolescent students. International Journal of Biomedical and Advance Research, 3, 9:714-719.

5. Danie T., L., Shek, \& Lu Yu (2012). Self-harmand suicidal behaviors in Hong Kong adolescents: Prevalence and psychosocial correlates. The Scientific World Journal: 1-14.

6. Ishita C. \& Jayanti B. (2010). Perceived causes of suicide, reasons for living and suicidal ideation among students. Journal of the Indian Academy of Applied Psychology, 36, 2:311316.

7. Amelia, M., A., Kevin, E., Grady, O., Kimberly, M., C., Kathryn, B., Vincent, H., C., Wilcox, \& Eric, D., W. (2009). Suicide ideation among college students: A multivariate analysis, Archives of Suicide Research, 13, 3:230-246.

8. Arun, P., \& Chavan, B., S. (2009). Stress and suicidal ideas in adolescent students in Chandigarh. Indian Journal of Medical Science, 63, 7: 281-287.

9. Liselotte et al., (2008). Burnout and suicidal ideation among U.S. medical students. Annals of Internal Medicine, 149, 5:334-341.

10. Crosby A., E., Cheltenham M., P., \& Sacks J., J. (1999). Incidence of suicidal ideation and behavior in the United States. Suicide Life Threat Behaviour, 29:131-40.

11. Rey, C., G., Narring, F., Ferron, C., \& Michaud, P., A. (1998). Suicide attempts among adolescents in Switzerland: Prevalence, associated factors and co morbidity. Acta Psychiatric Scandinavia, 98, 1:28-33.

12. Sharma, R., Grover, V., L., \& Chaturvedi, S. (2008). Suicidal behavior amongst adolescent students in south Delhi. Indian Journal of Psychiatry, 50, 1:30-33. 
13. Kunmi, S., Zhou N., A., J Fan, J., Liu, N., \& Sherer, R. (2014). Depression and suicidal ideation in medical students in China: a call for wellness curricula. International Journal of Medical Education, 5:31-36.

14. Chan, W., S., Law, C., K., Wong, P., W., Law, Y., W., \& Yip, P., S. (2009). Suicidality in Chinese adolescents in Hong Kong: The role of family and cultural influences. Social Psychiatry and Psychiatric Epidemiology, 44, 4:278-284. 